\title{
Choosing Appropriate Simulation Games in Industrial Engineering Education: 25 Years of Experience at the Centre for Industrial Management, K.U.Leuven
}

\author{
Ludo Gelders and Liliane Pintelon \\ Centre for Industrial Management, K.U.Leuven, Belgium
}

E-mail:Ludo.Gelders@cib.kuleuven.ac.be,liliane.pintelon@cib.kuleuven.ac.be

Key words: simulation games, industrial management, experience,learning

\begin{abstract}
The Centre for Industrial Management at K.U.Leuven introduced management simulation gaming as a teaching tool in the early seventies. Nowadays different types of games are used both for postgraduate education (in the Master of Industrial Management program) and in the undergraduate engineering curriculum. This paper reviews this experience and draws some conclusions. Our experience shows the necessity of simulation games in the educational proces, especially in management education. However, choosing a particular game implies constraints in contents, operating procedures, learning effects, etc.. That is why we have learned to distinguish between eyeopeners, hands on, single and multidisciplinary games which integrate different business disciplines. It should be said however that introducing and maintaining a battery of business games covering different educational objectives is a heavy burden, particularly with respect to manpower. Teamleaders with some business experience have our preference.
\end{abstract}

\footnotetext{
The original version of this chapter was revised: The copyright line was incorrect. This has been corrected. The Erratum to this chapter is available at DOI: 10.1007/978-0-387-35506-1_17
} 


\section{INTRODUCTION}

In this paper we present the conclusions of 25 years of experience with business games in the Industrial Management program at K.U.Leuven. This is a postgraduate program in management designed for (graduated) engineers. The one-year study program tries to establish a good balance between theory (ex cathedra courses) and practice (seminars, case studies, guest speakers, a thesis in industry and business games). During the past 25 years several games have been tested and, if interesting, have been introduced. Sometimes the games have been modified to better meet the specific needs of the program.

Games were and still are used for different purposes: e.g. a two-day game in which concepts from different courses are integrated, a smaller conceptillustrating game, a game just meant as an eye-opener, ... This will be explained into more detail below.

\section{AN INTEGRATED GAME}

Right from the start of the program in Industrial Management (it was founded in 1962) it was felt that theoretical courses should be complemented with practical experiences. For the latter different alternatives were introduced. First of all there were the traditional seminars with exercises on the theory. Further guest speakers from manufacturing and service industry were regularly invited. Another important addition was the thesis, which consisted (and still consists) of a real-life project in industry, to be solved by a team of two students. It was felt that still some more "practice" was needed and therefore business games have been introduced. At that time this was a rather new didactic concept in our engineering faculty.

The first business game used was a business war game from IBM. Different teams of students played the game, each team representing a company. The game integrated different management issues: procurement of raw materials, production planning, inventory management, marketing, price setting, investment decisions, financial reporting...

The game organization was as follows: weekly each team turned in its decisions for the next planning period, these data were fed into the computer (using punch cards and an IBM 1620 mainframe), results were handed back to the teams and the next game period was played the next week. In total, 10 to 12 periods were played (a semester).

Although the game, because of its integrated character, was very interesting, some major drawbacks were experienced. The batch procedure required a considerable time investment from the game leader: going to the 
university computer centre, punching the cards, checking for errors, submitting the job to the mainframe and waiting for the results. Possibly a more important drawback was the fact that the game often suffered from the difference in effort put into the game by the teams. Some teams had a weekly meeting to develop their strategy and based their decisions on a careful analysis of all data available, others only took a few minutes to fill out the required forms without caring too much about the desirability of their decisions. In the oligopolitic market situation, with 4 to 6 teams, this often lead to strange developments. Moreover the game leader felt that the game would not only benefit from a more equal effort by the teams, but also by some time pressure to make the decisions. This time pressure would force the teams to be better organised and would require a more structured analysis of the data available.

End of the seventies, we learned about the Eindhoven Shoe Game. The game was very similar as ours, but it was organised in a different way. The teams were playing about the same number of periods but now the whole game was concentrated on 2 or 3 days. This added the time pressure dimensions and ensured a similar effort by all teams. Another important observation was that the game was also very interesting from the point of view of team work and work organization. Some students, with sound theoretical knowledge, performed poor in the business game because of their lack of communication skills. The game also proved to be very rewarding for those who carefully planned and divided the work. If not, things would very quickly grow into a chaotic situation, with everybody working on everything and nothing being done properly. While students expect the game to be demanding on their planning skills, this communicationorganization part is very often underestimated.

A drawback of this new formula however was the rather intensive game supervision: a team leader for each team plus a central game coordinator. The team leader coaches his team (without telling too much...) and is responsible for the communication with the central coordinator. The latter made all necessary computations (e.g. sales per team based on marketing efforts), which was quite a burden.

An improvement in this respect was the computerization of the central game co-ordination, which was programmed on a HP85. Later on, and in co-operation with the Technical University Eindhoven, we improved the financial reporting part of the game. Still later, in 1982, the game was converted to a Turbo Pascal program running on a PC. Spreadsheets, first in Lotus 123, later on in Microsoft Excel, were developed for the students in order to help them with the routine work in the financial reporting, so that they could focus more on strategic issues. We observed however that for many teams this computer support was the start of developing other 
spreadsheets for analysis and decision support during the game. Often however, these spreadsheets were not carefully constructed and they led to a lot of new problems, which again divert the attention from the real game issues.

Students are motivated and enthusiastic to play and to "win". But it is not always clear what winning means: is it expressed in terms of market share, profit, assets,...?

We believe the traditional final feedback and evaluation session is an essential component of the overall learning process. During this meeting the different teams explain shortly the strategy of their company and they evaluate why their objectives have been attained or not.

All teams get feedback in their decision and their company's performance, and an overall analysis of the market with all competing firms is presented.

The feedback sessions develop a feel for a set of general business basics, e.g.

- winning the game depends also on the objectives

- your performance depends also on the competitions behaviour

- different organisations may lead to similar results

- etc. etc.

We still consider this game as a very good one, because of the integration of elements from different courses (production planning - investments financial reporting - marketing - ...). Students without working experience tend to find it hard to discover these links by just "studying the theory". Another strong point of this game is its reliance on communication skills and organizational choices, also aspects that are very important for the future career of our students.

The evolution from fully manual, over fully computerized, to partially computerized is also worth mentioning. Special attention should be paid to the fact that providing students with spreadsheets is not always beneficial for the game. This insight is particular useful for the students who tend to rely sometimes too much on the PC.

For the last years' mechanical engineering students we play a similar game, the Washing Machine Game, also developed at the Technical University Eindhoven. This game is similar to the previous one, but more focussed on production decisions e.g. scheduling and less extensive in financial reporting. Here also the game is considered to be an important asset in the educational process. 


\section{A CONCEPT TEACHING GAME}

In the early 80's, we also started (as everybody else) teaching the then new Japanese operations management techniques (such as JIT, TPM,...). We felt there was a need to give our students hands-on experience in some of these techniques. We bought from Philips the so-called JIT-game, using Lego and Duplo blocks. This well-known game allows to progressively teach concepts like impact of layout, WIP, reorder points, order quantities, order penetration point, quality, set-up times, added value profile, engineering changes, the use of kanbans,... This can be accomplished through production (and logistic) simulations with the Lego and Duplo blocks.

The game, although much appreciated by the students, has some drawbacks. First of all, the game calls for a trained and experienced coordinator in order to cope with the interactive progress ("what improvements for this production situations would you suggest?") and to deal with the surprises this way of working often brings. Moreover, the game material (number of blocks of each type, work instructions, kanbans, ...) not always permits to try out the suggested improvements or to carry out improvements that were either not standard in the game or are too time consuming to organise. Another drawback is the fact that only about 10 students can play at the time. This of course causes some problems in terms of manpower and scheduling if the group of students is large. Because a game proved to be a far more effective didactical tool than an ex cathedra class, we went to look for some alternatives. The results of this search are summarized in Table 1.

The traditional ex cathedra teaching has in this context the smallest impact on students. The film scores slightly better with this respect, especially with students with some industrial experience (they easily recognize the real-life aspects). A major drawback here of course is the fact that no interaction in terms of suggestions and experiences is possible. A classroom discussion afterwards may be used to remediate this drawback. While for watching the film the group of students may of course be very large, a profound discussion again calls for a rather small group.

A very interesting alternative, both in terms of learning power and manpower investment, is the tabletop JIT game. Here the products are sheets of papers on which computations (mental, with pen and paper, with calculator) are to be made. The game provides almost the same learning experience as the Lego-Duplo version, while asking far less preparation time and allowing much easier for try-outs of student's suggestions. 
Table 1: Alternative JIT-teaching schemes

\begin{tabular}{|c|c|c|c|}
\hline Alternative & description & $\begin{array}{l}\text { learning } \\
\text { power }\end{array}$ & $\begin{array}{l}\text { teaching } \\
\text { input }\end{array}$ \\
\hline Classroom & traditional ex cathedra teaching & $*$ & $*$ \\
\hline film (HP) or show & $\begin{array}{l}\text { film in which a Philips-like } \\
\text { simulation game is shown }\end{array}$ & $* *$ & $(*)$ \\
\hline table top game & $\begin{array}{l}\text { on-paper version of the Philips } \\
\text { game }\end{array}$ & $* * * *$ & $* * *$ \\
\hline Philips game & Lego/Duplo game & $* * * *$ & $* * * *$ \\
\hline
\end{tabular}

It does however not offer the same opportunities concerning e.g. added value profiles and cost structure. A special didactical feature here as well as with the Lego-Duplo version is the "natural" discussion on which criteria are relevant (e.g. WIP, throughput time, quality,...) and on how to measure them.

The Lego-Duplo blocks of the Philips game are also used in a seminar on buffer size and location in a transfer line. Here the visual effect of the wrong choices is made very apparent with these blocks.

\section{AN EYE-OPENER GAME}

During a joint research program with the University of Cardiff, we had the occasion to experiment with the Beer Game, one of the oldest simulation games (developed in the US). We decided to introduce this game as a vehicle to give the students - before any teaching in this domain - a feel for the bullwhip effect. The recent interest for supply chain management was certainly a stimulus into that direction. The Beer Game is an excellent tool to illustrate the amplified order and inventory variability in a logistic chain. We are currently looking into the possibility to offer this game as a PC-game to the students as part of a self-study package. 


\section{OTHER GAMES}

\subsection{Commercially available games}

Management needs are evolving on time, therefor an Industrial Management program should try to respond to the changing needs. That means, among others, investigating new potential games for the curriculum. Over the years we tested quite a few games. Some were used for a while, e.g. a TOC game on PC, and others have never been scheduled for a variety of reasons: too easy, too specific, unclear instructions, requiring too much manpower, etc.

Besides the production-logistic games described above, there is currently a socio-psychological game, in which students play roles of stake-holding groups in a town (environmentalist, industry, town council,...). These groups have to decide on what to do with a limited budget. Focus is here on communication and negotiation skills.

Currently, we are studying a few alternatives in the area of project management.

Besides the traditional scheduling aspect, managerial aspects should also be included.

\subsection{Game development}

Recently, we also made some preliminary contacts with the department of Traffic and Infrastructure of our University for the joint development of a mobility game.

If we view the transportation process from a logistic point of view we can distinguish several components with many interdependencies. This requires a high degree of co-operation, organization and mutual adjustment. Several interest groups play their part in the organization of this process such as carriers, shippers, customers, operators of the network, governmental agencies, trade branch organizations and others. The ultimate quality of the offered service strongly depends on the organization and co-ordination of the different activities. All the actors involved have their own responsibilities. A sound co-operation between the parties is an essential condition. Proposals to improve the process necessitate intensive consultations and an understanding of the other parties' motives. Innovation in logistics mostly adds up to an improvement in the processes employed rather than in the mechanical contents. The challenge here is to develop a game in which the different actors or stakeholders who bear responsibility in the real system are actively involved in a simulation using a set of agreed upon rules. 
The game will be used for several purposes:

- using game simulations to improve communication

- using game simulation to improve the efficiency of the decision process

- using game simulation to test for the robustness of an approach

- using game simulation to try out new approaches

It would appear that game simulation is an ideal tool to use in the intricate and multi-functional world of logistics.

\section{CONCLUSIONS}

Our experience shows the usefulness, even the necessity, of simulation games in the educational process of a management program. However, choosing a particular game implies constraints in contents, operating procedures, learning effects, etc... That is why we have learned to distinguish between eye-openers, hands on, single and multidisciplinary games, which integrate different business disciplines. It should be said however that introducing and maintaining a battery of business games covering different educational objectives is a heavy burden, particularly with respect to manpower.

However, we are convinced - and this is confirmed by the feedback of students and ex-students - that simulation games are indispensable tools in management education.

\section{REFERENCES}

Pintelon L., Gelders L., and Van der Heyde C. (1997) "Structured Field Research for Master's Theses”, European Journal of Engineering Education, vol.22, n4, 1997, pp 435-444. Elgood C. (1984) Handbook of Management Games, Gower Press, London, 1984.

\section{BIOGRAPHY}

\section{Ludo Gelders}

Prof. Ludo F. Gelders holds degrees in electromechanical engineering (University of Ghent) and industrial management (Université Catholique de Louvain). After work experience as an industrial engineer in jet-engine manufacturing, he studied at the MIT-Sloan School (USA) and got his doctoral degree in industrial management at K.U.Leuven. 
Currently he is full professor at the Centre for Industrial Management at Katholieke Universiteit Leuven (Belgium). He served as chairman of the department of Mechanical Engineering and as chairman of the Centre for Industrial Management, both at K.U.Leuven. He published over 100 articles on logistics, maintenance, quality and production and holds editorial responsibilities in several international journals. He is a director of the Dutch Research School on Operations Management BETA. He is a former president of the Royal Flemish Engineering Society (KVIV) and currently serves as vice president of the Belgian Academy Council for Applied Sciences.

He was a consultant to several international corporations.

\section{Liliane Pintelon}

Liliane M.-Y. A. Pintelon holds degrees in Chemical Engineering (1983) and Industrial Management (1984) of the KULeuven (Catholic University of Leuven, Belgium). In 1988-1989 she worked as a visiting research associate at the W. Simon Graduate Business School (University of Rochester, USA). She obtained her doctoral degree in industrial management (maintenance management) from the KULeuven in 1990. Currently, she is associate professor at the Centre for Industrial Management (KULeuven).

Her research and teaching area is industrial engineering, with a focus on maintenance management. She also has a considerable experience as an industrial consultant in this area. 